\title{
Waiting for lumbar spinal stenosis surgery: suffering and a possibility to discover coping abilities
}

\author{
Björn Knutsson, MD, Ph.D. ${ }^{1}$ a, Mats Jong, PhD², Arkan Sayed-Noor, MD, Ph.D. ${ }^{3}$, Göran Sjödén, MD, Ph.D. ${ }^{3}$, \\ Marika Augutis, Ph.D. ${ }^{4}$ \\ 1 Department of Surgical and Perioperative Science, Umeå University, ${ }^{2}$ Department of Health Sciences/Public Health, Mid Sweden University, ${ }^{3}$ \\ Department of clinical science and education, Södersjukhuset, Karolinska Institutet Stockholm, ${ }^{4}$ Department of Neurobiology, Care Sciences and \\ Society. Division Clinical Geriatrics, Karolinska Institutet, Stockholm \\ Keywords: spinal stenosis, coping, patient-physician relationship, patients' experience of care \\ https://doi.org/10.52965/001c.30716
}

\section{Orthopedic Reviews}

Vol. 14, Issue 1, 2022

\section{Objective}

The objective of this study was to describe aspects of suffering related to being a person with LSS and how suffering is managed before LSS surgery.

\section{Methods/design/setting}

A Swedish county hospital. Interviews with 18 consecutive patients on the waiting list for LSS surgery. The themes that emerged from content analysis were further interpreted using Antonovsky salutogenic model as a sensitizing concept.

\section{Results}

The suffering from LSS before surgery included the main theme of experiencing an impaired physical and social life and struggling to be believed and taken seriously. This had coping strategies to manage symptoms before surgery: a good physician-patient relationship alleviates the burden of long waiting times; ways to manage pain and disability; ambiguous expectations and hope for recovery, and; ways to handle concerns before surgery).

\section{Conclusion}

Being a person with LSS includes suffering and a possibility to discover coping abilities or having support structures for doing so. Our study emphasizes the importance of a supportive dialogue, where physicians and patients make the suffering from LSS and care before LSS surgery more comprehensible and manageable.

\section{INTRODUCTION}

Lumbar spinal stenosis (LSS) is common in the elderly, and surgery for LSS has become the most common indication for spine surgery in many countries. ${ }^{1-3}$ The conditions is associated with impaired quality of life comparable to stroke, heart-related diseases, and diabetes. ${ }^{4}$ From a patient's perspective, LSS can be experienced as a world of suffering: illness-suffering due to pain and impaired function or from being on a waiting list for surgery are obvious forms of suffering. But also caring-suffering and life-suffer- ing are of major importance. Caring-suffering can be described as suffering due to care, for example, patients experiencing feelings of not being believed or not being taken seriously. Life-suffering comprises experiences of a threatened life situation like the uncertainty of the world and loneliness. ${ }^{5,6}$

An individual's attempt to manage suffering and demands created by stressors is often referred to as coping. These efforts seek to manage, master, tolerate, reduce, or minimize the demands of a stressful environment. ${ }^{7}$ The sociologist Aaron Antonovsky described his theory of salu-

\footnotetext{
a Corresponding author:

Björn Knutsson

Department of Orthopedics Hospital of Sundsvall, Lasarettsgatan 21, 85643 Sundsvall, Sweden.

Email: bjorn.knutsson@umu.se.

Phone number: +4660181778 .
} 
togenesis in 1979. The theory originated from interviews with survivors from the Holocaust and raised the question: How can we survive despite all the chaos and stress experienced. ${ }^{8}$ Furthermore, Antonovsky's salutogenic model, including but not restricted to coping abilities, describes the importance of general resources of resistance (GRRs) for dealing with stressors and, in that sense, also focusing on supporting health. ${ }^{8}$ Typical GRRs are wealth, physical strength, knowledge-intelligence, ego identity, coping strategies, social support, commitment, cultural stability, religion or philosophy, and preventive health orientation. Through strong GRRs, life stressors can be comprehensible, manageable, and meaningful, which gives a sense of coherence (SOC). This capacity is relatively stable over time and increases with age. Depending on the context, stressors, and available GRRs, SOC can be dynamic, at least shortterm. A strong SOC is associated with life satisfaction, perceived health, mental health, high quality of life, and better function after surgery for LSS. ${ }^{8-13}$ Furthermore, the salutogenic model has become an important tool both for quantitative and qualitative research. $8,9,12,14-16$

Although studies exclusively for patients with LSS are uncommon, several qualitative studies on low back pain (LBP) and sciatica have described the experiences and expectations from a patient's perspective. These studies stress the importance of patient-centered care, including a diagnosis, being believed, and adequately investigated. ${ }^{17-19}$ In contrast to LBP and sciatica, LSS is a specific diagnosis, and patients are generally older. In addition, the patients in the present study are waiting for surgery which makes the context different from the suffering due to LBP or sciatica. The objective of this study was to describe aspects of suffering related to being a person with LSS and how suffering is managed prior to LSS surgery.

\section{MATERIAL AND METHODS}

The study had a qualitative inductive approach whereby the interview transcripts were analyzed by content analysis. The content analysis aims to capture the core of the interviews and explore differences and similarities in the transcribed text. ${ }^{20}$

During the study period (October - December 2013), eighteen consecutive patients on the waiting list for LSS surgery at a Swedish county hospital were recruited. All patients agreed to participate. Our inclusion criteria were age $\geqslant 18$ and good knowledge of the Swedish language. $\mathrm{Pa}-$ tients with dementia were not eligible for the study. A few days after the patient was scheduled for surgery, a specific research nurse gave information about the study and obtained informed consent. The nurse was not involved in the care of the patients.

The interviews were performed at the patient hostel, providing a more neutral environment than the orthopedic outpatient department or ward. The interviewer (BK) was dressed in casual clothing. Interviews lasted for 60-90 minutes. The individual face-to-face interviews started with structured questions on socio-demographic and medical information. This was followed by open-ended questions used to stimulate a dialogue on the topic under study. An interview checklist was used to compromise broad domains, i.e., care, patient perspective on experiences and feelings from LSS, and expectations before surgery. Interviews were digitally recorded and later transcribed verbatim.

\section{DATA ANALYSIS}

All authors read all interviews transcripts, and first impressions were discussed and documented. The next step was to condense (shorten but still preserve the core concepts) the transcripts into meaningful units, further aggregated (interpretation on a higher logical level). These codes were aggregated into categories, which additionally created themes. ${ }^{20} \mathrm{~A}$ validation and verification process by a consensus strategy was performed, whereby the authors discussed and reexamined coding discrepancies in a further effort to reach consistency. In addition, a content validation with an external experienced qualitative researcher was performed to support the inductive category and theme application. ${ }^{20}$

To explain the patterns that had emerged during the analysis, we explored the data from different theoretical perspectives. Several descriptions of coping mechanisms, GRRs, and descriptions of the patients' resources were found in the interviews. Hence the discussion section presents our interpretation of the categories and themes using the salutogenic model as a sensitizing concept. ${ }^{8,9,21}$ Patton points out sensitizing concepts as possibilities for alternative interpretations. ${ }^{21}$

Citations are presented throughout the results section to increase the credibility further.

The content analysis was performed with NVivo, version 10 , as a support tool.

\section{ETHICAL CONSIDERATIONS}

The Regional Ethics Review Board approved the study. Patients gave informed consent and were granted confidentiality. The interviewer (BK) was also the forthcoming surgeon. This could be considered an ethical problem, but all patients were on the waiting list for surgery and assured that the interview could not affect the planned surgery or follow-up. Finally, patients were informed that they could terminate their participation in the study at any time. None of the other authors participated in the care of the patients.

\section{RESULTS}

On average, the interview took place 59 days (range 1-118) before surgery. The common clinical complaint for all patients were symptoms of neurogenic claudication or radicular leg pain. Seven patients had spinal stenosis, eight had spinal stenosis with degenerative spondylolisthesis, and three had spinal stenosis with isthmic spondylolisthesis. Twelve patients were treated with decompression, and seven were treated with decompression and instrumented posterior-lateral fusion. One patient canceled the scheduled surgery due to improved symptoms. Eleven patients 
Table 1. Baseline characteristics of the eighteen interviewees

\begin{tabular}{ll}
\hline Female gender & $\mathrm{N}=11$ \\
\hline Age, mean (SD) & $66(11)$ years \\
\hline Smoking & $\mathrm{N}=2$ \\
$\quad$ Current & $\mathrm{N}=16$ \\
$\quad$ Non-smoker & \\
\hline Occupation & $\mathrm{N}=1$ \\
$\quad$ Factory worker & $\mathrm{N}=2$ \\
Cleaner & $\mathrm{N}=1$ \\
Teacher & $\mathrm{N}=1$ \\
Nurse & $\mathrm{N}=8$ \\
Retirement pension & $\mathrm{N}=5$ \\
Disability pension & \\
\hline Marital status & $\mathrm{N}=14$ \\
Partnership & $\mathrm{N}=4$ \\
Living alone & \\
\hline Comorbidities & $\mathrm{N}=11$ \\
Hypertension & $\mathrm{N}=2$ \\
Heart disease & $\mathrm{N}=3$ \\
Lung disease & $\mathrm{N}=7$ \\
Diabetes & $\mathrm{N}=1$ \\
Depression & $\mathrm{N}=1$ \\
Rheumatoid arthritis & $\mathrm{N}=1$ \\
Muscle rheumatism & $\mathrm{N}=1$ \\
Osteoporosis & $\mathrm{N}=2$ \\
Prostatism & $\mathrm{N}=1$ \\
Ulcerative colitis & \\
\hline
\end{tabular}

One interviewee could have several comorbidities.

had one level, and seven patients had two-level spinal stenosis. Since the symptoms from LSS typically develop over time, few patients could give an exact time for their current symptoms. One patient reported $<6$ months, eight 6-12 months, five 13-24 months, and three 25-36 months of current pain. One patient reported "long duration of pain" without any definition in time. The mean age was 66 years (range 35-83), and most of the patients were females $(n=11)$. Somatic comorbidity was common, and most patients were retired $(n=13)$. A description of the patients' characteristics is summarized in table 1.

The themes identified in the content analysis are presented in turn as follows.

\section{EXPERIENCING AN IMPAIRED PHYSICAL, SOCIAL AND EMOTIONAL LIFE}

The pre-symptomatic experience of patients provided a context for their current suffering. Patients described having had an active physical life before the symptoms from LSS became severe. Different kinds of activities such as hiking, hunting, or fishing were mentioned, exemplifying how strong and reliable their legs used to be. In the present, patients described their substantial suffering, including limited leg function, leg pain, paresthesia, and numbness:

I can only stand for 10 minutes, a quarter of an hour at the most; I can't stand any longer than that. I think that I have to go and sit down somewhere. There is a burning sensation in my legs, and something goes numb. I can feel it burn. It's like I lose all feeling in my legs.
The pain and limited function were also associated with sleep disturbances. Feelings of shame in front of other people when their body did not function correctly were also expressed in the interviews:

I went up into the forest rather than walking along the road because people would think that I wasn't sober.

My legs are going this way, and the upper part of my body is going that way. It was embarrassing.

Pain limited function in household chores and at work. Suffering from a restricted daily life and an undesired sedentary lifestyle were common. One patient outlined the loss of his pre-symptomatic daily walk:

I can't say that I'm depressed or anything. I'm not, but
it's like I can't quite find the rhythm. A good pattern is
to go out for a long walk in the morning, then you come
home and have lunch, and then there's this time of re-
laxation in the afternoon when I can sit down and read.

The undesired sedentary lifestyle could also be perceived as a factor for weight gain due to impaired function and walking ability.

I I ought to lose a few kilos, but I can't walk.

The interviewees described the isolation and how it affected relationships with family and friends. Due to symptoms from LSS, partnerships were described as being altered, i.e., using separate bedrooms and a restriction in their sex life:

We have an active sex life ... There have been situations when my back specifically has been aching - ouch and oh, no - and we've had to stop because of it.

\section{A GOOD PHYSICIAN-PATIENT RELATIONSHIP ALLEVIATES THE BURDEN OF LONG WAITING TIMES.}

Long waiting times for magnetic resonance imaging (MRI), an appointment with a surgeon, and surgery were concerns in many interviews. A good physician-patient relationship was perceived as a resource, which alleviated the consequences of disability, suffering, and being on a waiting list:

My health care center is XX, then she sent me to have a lumbar X-ray, and after that, I had to wait for a long, long time. But I have a fantastic doctor, I do.

In contrast, misinformation, appointments with different unknown physicians, separate waiting times for MRI, and an appointment with a surgeon increased the suffering of long waiting times. The patient's situations of dependence and vulnerability in the relationship with the physician were expressed in several interviews:

I hope they operate. It isn't certain that they'll perform the surgery... then you have to live with it. That also made me worried. 


\section{STRUGGLING FOR BEING BELIEVED AND TAKEN SERIOUSLY}

Continuity in care was important for feelings of trustworthiness among patients. Some patients described a struggle against the healthcare system and feelings of not being believed:

Yes, because they said that I am as usual, that I'm whole, healthy. I didn't feel like that myself. I wanted to know what was wrong. I knew that there was something wrong.

Some patients also experienced discrimination due to age, obesity, or former alcohol abuse.

I was too fat, and I was too old.

When the information from physicians was experienced as insufficient, the internet was described as a source of information. However, the retrieved information was described as sometimes difficult to understand and interpret. The internet and other sources of information could contribute to knowledge and understanding, even if personal information and dialogue with the surgeon were described of significant importance:

Yes, the person performing the surgery is the most important. Yes, I think so. You know what you're doing.

All patients described the MRI before referral to a spine surgeon as very important for confirmation. Both as confirmation that their suffering was real and to receive a diagnosis that explained the symptoms they were experiencing:

I was really happy that they finally found something. It wasn't all in my head.

To receive the diagnosis of LSS was also perceived as necessary as it excluded worse conditions such as cancer.

\section{WAYS TO MANAGE PAIN AND DISABILITY}

The patients described several ways to manage the disease. One way was to compare themselves and someone else they knew who had worse problems. Another way of handling the situation was to focus more on things that were experienced as positive:

I can walk, that's what I keep telling myself. I can still do a lot of things.

Several patients described their ability to use their resources in the sense of a "fighting spirit." Furthermore, performing duties for other people, their animals, or work was common and expressed as important to keep them going. Even though only five of the patients were employed, work was explained as important to break the isolation and boredom:

The social part is important. You'll climb the walls otherwise ... you're used to working.
Different forms of physical activities, like biking indoors or outdoors, were described as ways to manage the everyday situation:

I thought maybe exercise would cure it. I've been seeing a physiotherapist ... I'm happy about that anyway.

Walking aids like a walking frame were important for managing shopping and visiting public places. One patient describes the positive implications of having community companions:

Tuesdays and Thursdays, I have a companion. It's great. If I want to go shopping, that's what we do. If we want to walk around town, that's what we do.

Furthermore, the church was described as important for social interaction:

Go to church, meet lots of people ... have coffee and a chat ... Being around other people and meetings

\section{AMBIGUOUS EXPECTATIONS AND HOPE FOR RECOVERY}

A concrete and common expectation was improved leg function and reduced leg pain. However, expectations could also be more generic like:

I want to get well

Some patients described a combination of modest expectations and expectations of full recovery after surgery:

An ordinary life; where you do things at home, you clean, do the laundry, potter about, it doesn't have to be anything special. Just an ordinary life is the expectation. To be able to travel a bit. To be able to trust your legs.

Compared to an earlier quote from the same person:

| That I'll get to go running in the forest, into the forest.

\section{WAYS TO HANDLE CONCERNS BEFORE SURGERY}

Some patients described fear for complications like infection, anesthesia awareness, or using a wheelchair after surgery. In contrast, several patients describe no worries at all before surgery:

I'm not the type to worry.

Due to severe suffering, some patients described the surgery as the only option left. Furthermore, earlier positive experiences from healthcare and friends successfully operated on for LSS were vital to handling the stress before surgery.

I also have neighbors in the country and another acquaintance who have had this surgery, and they've given me fairly good accounts. For all three people that I know, it's gone well. 


\section{DISCUSSION}

To endure the consequences of LSS includes aspects of being physically restricted, isolated, and emotionally impaired. In other words, the disease had a profound impact on the person suffering from it. The patients of this study described not only what their suffering meant to them, but they also described how they found resources that helped them to manage the disease. LSS can become comprehensible if they feel that they are being believed and taken seriously. ${ }^{15}$ The patients emphasized that the orthopedic surgeon and other health care staff played a crucial role in helping them cope. Ways to manage the experienced pain and disability are described in the results, and we have chosen to represent them as resources for comprehensibility, manageability, and meaningfulness from a salutogenic standpoint.

GRRs can originate from different levels: on a legislative level, the Swedish health care system is equitable, available to all citizens, and patient-centered care is statutory. According to Antonovsky, these are important community resources for a high SOC. ${ }^{8}$ Furthermore, on a community level, municipalities can provide individuals suffering from disabilities with community companions, walking aids, home adaptations, and other tools to make life more manageable. On the personal level, social support from family and friends is essential, and although Sweden is a secular society, the church was seen to be important for social interaction. In addition, other people's experiences of surgery and healthcare could ease the concerns before the surgical procedure. Few interviewees were employed but staying at work has been described as a way to cope with chronic LBP and sciatica. ${ }^{22}$

Our results also stress a good physician-patient relationship, based on patient-centered care, including continuity, proper treatment, investigations, examination, and information/dialogue, gives more satisfied patients. ${ }^{18,23-26}$ In agreement with previous studies, an established diagnosis and a known cause for the pain is important for the patient to understand and accept their symptoms. In contrast, delegitimization (feelings of not being believed or denied) is associated with dissatisfaction, thereby caringsuffering. ${ }^{5,6,17-19}$ A diagnosis is also important to exclude severe spine pathology, especially in the elderly with a high frequency of comorbidities. Furthermore, information is an important and complex issue. Timely and knowledge-based information should be provided from the treating physician and operating surgeon to enhance comprehensibility and trust. 8,18

Expectations of recovery from surgery may be the strongest source for the interviewee's capacity to see meaningfulness in everyday life. Even if improved leg function and decreased leg pain were common goals, some of the expectations were similar to how life used to be perhaps 5-10 years earlier or for healthy individuals of their age. This captures the importance of relevant expectations and consistent and precise information.

Many earlier studies have relied on the pathogenetic paradigm, i.e., a medical disease model. The disease model's center is a dichotomous classification of individuals as diseased or healthy. The salutogenic patient-centered approach is a model that guides health promotion by shifting attention towards the individual's resources and strengths. Living with LSS is a physical, mental, and social challenge, and resources to cope with the suffering may be more important than a full recovery. ${ }^{18,27,28}$

The main strengths of this study are the defined context and sampling method. All eligible patients accepted the offer to participate, representing various life experiences. ${ }^{20}$ $\mathrm{BK}$ as the interviewer is a conceivable limitation, as he was the forthcoming surgeon, and this may have resulted in observer bias. However, to minimize this, all authors analyzed the interviews, and an external observer validated the results from the content analysis. Furthermore, the quotations translated by an external assistant who had a Bachelor of education in Swedish and English increased the credibility. Although SOC is a validated quantitative measure and has been applied as a theoretical framework for qualitative research, the theory has limitations: the direction of the causality between SOC and health is uncertain, and SOC could be a measure of physical and mental health instead of a predictor for health.

To explain the patterns in the data, we need a framework. Several descriptions of coping mechanisms, GRRs, and descriptions of the patients' resources were found in the interviews. Therefore, we considered Antonovsky's salutogenic theory to fit the data. Hence, we presented our interpretation of the categories and themes using the salutogenic model as a sensitizing concept. Nevertheless, the choice of framework is influenced by the pre-understanding of the authors and emphasizes the experiences from a salutogenic perspective.

\section{CONCLUSION}

Being a patient with LSS includes suffering and being a person with their resources, able to discover their coping abilities, or having support structures for doing so. Our study emphasizes the importance of a supportive dialogue, where physicians and patients make the suffering from LSS and care before LSS surgery more comprehensible and manageable. Future studies should focus on whether patient involvement in care-like models for shared decision-making increases patients' satisfaction with care and the patients' reported outcomes after surgery for LSS.

\section{CONTRIBUTIONS}

BK conceived the study. All authors contributed to the study's design, interpretation of the data, and manuscript revision. BK, MJ, and MA analyzed the data, and BK drafted the manuscript. All authors had full access to all data in the study and took responsibility for the integrity of the data and the accuracy of the analysis. BK is the guarantor. All authors approved the final manuscript. 
The first author's dissertation published a summary of the findings (Knutsson, B. 2015. Lumbar spinal stenosis. Body mass index and the patient's perspective).

\section{FUNDING}

The work was supported by the Department of Research and Development Västernorrland County Council.

\section{COMPETING INTERESTS}

All authors have completed and submitted the ICMJE Form for Disclosure of Potential Conflicts of Interest. Dr.
Knutsson, Profs Sayed-Noor, and Sjödén report grants and personal fees from the Department of Research and Development Västernorrland County Council. The Department of Research and Development, Västernorrland County Council, is financial support from a non-profit organization without any potential conflict with our publication.

Submitted: August 26, 2021 EDT, Accepted: September 30, 2021 EDT 


\section{REFERENCES}

1. Deyo RA, Mirza SK, Martin BI, et al. Trends, major medical complications, and charges associated with surgery for lumbar spinal stenosis in older adults. JAMA. 2010;303(13):1259-1265. doi:10.1001/jama.20 10.338

2. Du Bois M, Szpalski M, Donceel P. A decade’s experience in lumbar spine surgery in Belgium: sickness fund beneficiaries, 2000-2009. Eur Spine J. 2012;21(12):2693-2703. doi:10.1007/s00586-012-238 $\underline{1-1}$

3. Strömqvist B, Fritzell P, Hägg O, Jönsson B, Sandén B. Swespine: the Swedish spine register. Eur Spine J. 2013;22(4):953-974. doi:10.1007/s00586-013-2758-9

4. Battié MC, Jones CA, Schopflocher DP, Hu RW. Health-related quality of life and comorbidities associated with lumbar spinal stenosis. Spine J. 2012;12(3):189-195. doi:10.1016/j.spinee.2011.11.009

5. Eriksson K. Understanding the world of the patient, the suffering human being: the new clinical paradigm from nursing to caring. Adv Pract Nurs $Q$. 1997;3:8-13.

6. Lindholm L, Eriksson K. To understand and alleviate suffering in a caring culture. J Adv Nurs. 1993;18(9):1354-1361. doi:10.1046/j.1365-2648.199 3.18091354.x

7. Lazarus RS. Coping theory and research: past, present, and future. Psychosom Med. 1993;55(3):234-247. doi:10.1097/00006842-19930500 0-00002

8. Antonovsky A. Health, Stress and Coping. 1st ed. Jossey-Bass Publishers; 1979.

9. Antonovsky A. Unraveling the Mystery of Health. 1st ed. Jossey-Bass Publishers; 1987.

10. Eriksson M, Lindstrom B. Validity of Antonovsky's sense of coherence scale: a systematic review. $J$ Epidemiol Community Health. 2005;59(6):460-466. do i:10.1136/jech.2003.018085

11. Eriksson M, Lindstrom B. Antonovsky's sense of coherence scale and the relation with health: a systematic review. J Epidemiol Community Health. 2006;60(5):376-381. doi:10.1136/jech.2005.041616

12. Eriksson M, Lindstrom B. Antonovsky's sense of coherence scale and its relation with quality of life: a systematic review. J Epidemiol and Community Health. 2007;61:938-944.
13. Sinikallio S, Lehto SM, Aalto T, Airaksinen O, Viinamäki H. Low sense of coherence interferes with lumbar spinal stenosis patients' postoperative recovery: a prospective one-year follow-up study. J Health Psychol. 2011;16(5):783-793. doi:10.1177/1359 105310390723

14. Nyman P, Palenius K, Panula H, Mälkiä E. Patients' experiences of shoulder problems prior to and following intervention. Physiother Theory Pract. 2012;28(3):221-231. doi:10.3109/09593985.2011.5982 $\underline{20}$

15. Oliveira CC. Suffering and salutogenesis. Health Promot Int. 2015;30(2):222-227. doi:10.1093/heapro/d $\underline{\mathrm{au} 061}$

16. Persson L, Larsson G, Ohlsson O, Hallberg IR. Acute leukaemia or highly malignant lymphoma patients' quality of life over two years: a pilot study. Eur J Cancer Care (Engl). 2001;10(1):36-47. doi:10.104 6/j.1365-2354.2001.00236.x

17. Davis RE, Vincent C, Henley A, McGregor A. Exploring the care experience of patients undergoing spinal surgery: a qualitative study. J Eval Clin Pract. 2013;19(1):132-138. doi:10.1111/i.1365-2753.2011.01 783.x

18. Hopayian K, Notley C. A systematic review of low back pain and sciatica patients' expectations and experiences of health care. Spine J. 2014;14(8):1769-1780. doi:10.1016/j.spinee.2014.02.0 29

19. Ong BN, Konstantinou K, Corbett M, Hay E. Patients' own accounts of sciatica: a qualitative study. Spine (Phila Pa 1976). 2011;36(15):1251-1256. doi:10.1097/brs.0b013e318204f7a2

20. Graneheim UH, Lundman B. Qualitative content analysis in nursing research: concepts, procedures and measures to achieve trustworthiness. Nurse Educ Today. 2004;24(2):105-112. doi:10.1016/i.nedt.2003.1 $\underline{0.001}$

21. Patton M. Qualitative Research and Evaluation Methods. 4th ed. SAGE; 2014.

22. de Vries HJ, Brouwer S, Groothoff JW, Geertzen JHB, Reneman MF. Staying at work with chronic nonspecific musculoskeletal pain: a qualitative study of workers' experiences. BMC Musculoskelet Disord. 2011;12(1):126. doi:10.1186/1471-2474-12-126 
23. Glass RM. The patient-physician relationship. JAMA focuses on the center of medicine. JAMA. 1996;275(2):147-148. doi:10.1001/jama.275.2.147

24. Hjortdahl P, Laerum E. Continuity of care in general practice: effect on patient satisfaction. BMJ. 1992;304(6837):1287-1290. doi:10.1136/bmj.304.683 $\underline{7.1287}$

25. Lærum E, Indahl A, Sture Skouen J. What is "the good back-consultation"? A combined qualitative and quantitative study of chronic low back pain patients' interaction with and perceptions of consultations with specialists. J Rehabil Med. 2006;38(4):255-262. d oi:10.1080/16501970600613461
26. Laine C, Davidoff F. Patient-centered medicine. A professional evolution. JAMA. 1996;275(2):152-156. $\underline{\mathrm{d}}$ oi:10.1001/jama.1996.03530260066035

27. Collis D, Waterfield J. The Understanding of Pain by Older Adults Who Consider Themselves to Have Aged Successfully. Musculoskelet Care. 2015;13(1):19-30. doi:10.1002/msc.1083

28. Huber M, Knottnerus JA, Green L, et al. How should we define health? BMJ. 2011;343:d4163. doi:1 0.1136/bmj.d4163 